\title{
Research on the Information Management Major Construction under the New Engineering Background of China
}

\author{
Xufang Li \\ School of Management \\ Shanghai University of Engineering Science \\ Shanghai, China \\ lucylxf@163.com
}

\author{
Chang Lu \\ DELIX Specialty for Equipment \\ Shanghai, China \\ sophyia9@163.com
}

\begin{abstract}
With the development of economy in China, the society has put forward new capacity requirements for engineering education. In this environment, the New Engineering has distinct epochal significance. Based on the basic idea of New Engineering construction, respectively from the three aspects of promoting new major construction, existing major reform and cross-integration majo $r$ construction, this paper discussed how to update the basic education concept of information management major to meet the new demands of New Engineering construction.
\end{abstract}

Keywords-New Engineering; major construction; major reform; information management

\section{INTRODUCTION}

The ministry of education has started research works of the development of "the New Engineering" in 2017. And on February 18, it's formed “"New Engineering' building Fudan consensus”. On April 8, “New Engineering' course of action (the action of Tianjin University) has been formed". The ministry of education repeatedly emphasized that we should focus on the strategy of national development, and under the new situation it's important for us to seize opportunities of cultivating talents. Meantime, it also highlighted the reform of deepening on advanced engineering education completely, the construction of New Engineering and we should take the initiative to look into the future as well as adapt and lead to the new economy. Constructing New Engineering has set off a new wave of reform in academic community of China. There are many universities have made generous response to it, so do industry and international.

In fact, the new developmental approaches of engineering education are always explored by Chinese and other countries' researchers. In 2010, National Academy of Engineering presented the "2020 Engineer" research project ${ }^{[1-2]}$. In 2004 and 2005, it released some reports, like "2020 Engineer: the Vision of New Century Project”, “Training 2020 Engineer: Reforming of Engineering Education for New Century” and so on. Accreditation Board for Engineering and Technology (ABET) pointed out clearly in "Engineering Principles 2000" that engineering talents must be able to identify, explain, resolve problems of engineering and use technologies, skills and modern tools in practice. The CDIO engineering education capability program, which was jointly came up with by MIT, claimed that engineering graduates enabled to think, design, implement and operate complex and valuable engineering system in a modern team. Meanwhile, they might possess professional knowledge and practical ability, and lay emphasis on comprehensive ability to solve problems and scientific innovation $^{[3]}$. For more than 10 years, our country always explores new way to engineering education, for example, founding national demonstration software institute, establishing microelectronics college, implementing the excellent engineer training plan, pushing CDIO engineering education, carrying out engineering education professional certification, developing related major of strategy of emerging industry and so on ${ }^{[4]}$. The state council established "the Enforcement Advice on Deepening Reform of University Innovation and Entrepreneurship Education" and "General Planning on Boosting World-class Universities and First-class Disciplines" in 2015 and put forward innovation-driven development strategy of China. At the same time, the state council presented to deepen reform of higher education in innovation and entrepreneurship. And it stipulated to cultivate innovative, application-oriented and versatile talents with historical mission sense and social responsibility, innovative spirit and practical ability. It aims to meet needs of cultivating the current and future emerging strategic industries competition talents and lays the solid foundation for the development of New Engineering education.

\section{SEIZING OPPORTUNITIES TO IMPROVE CONSTRUCTION OF NEW PROFESSIONS}

With the improvement of new industries, formats, technologies and modes in economy ${ }^{[5]}$, the ministry of education added 4 specific majors, including data science and big data(080910T), network space security(080911TK), new media technology(080912T), film production(080913T) and so on in 2016, to adapt well to the requirements of big data technology talents of society. These special professions will become the new growth points and they should satisfy "National Standards for Teaching Quality of Undergraduate Majors in Ordinary Institutions of Higher Education”, which issued by the ministry of education on January 30, 2017. Specially, it must satisfy some recommends. 
First, it should define the social requires of majors. Generally speaking, the New Engineering construction's purpose is to develop graduates who meet social needs, "building majors according to industries' needs", "reforming contents on the basis of technical development", and intensify the industry-academy cooperation. Graduates have their own subspace of problems for each profession. This subspace reflects essential services that cultivate students for majors and show their advantages. Therefore, it's not the whole space, but also it's not the same majors' subspace of problems in other universities. And it requires that sponsors of applying for the professions ought to make it clear that related graduates who are developed by this major will meet social needs. The need is not general requires or downloading online. It aims to cultivate qualified person for subspace of problems.

Second, it's necessary to establish a reasonable project that develops talents. It has a target to reflect students' discipline superiority and match with "subspace of problems" making sure that students' professional expectation in about 5 years instead of a general goal which set in graduating in the field, including science research, engineering development, application maintenance, teaching and management. Then it needs to have professional graduation requirements to support the training goals. Graduation shouldn't lower than requirements given by ministry of education. And it needs to have its characteristics. Having precise targets, it will reflect talents' features. It can support the curriculum system of professional graduation requirements effectively. It needs to be broken down into indicator points and assigned tasks to corresponding courses (theoretical courses and practical courses). What's more, each new major should have its own specialties rather than only one "aspect" to information management and information system or even not a new professional curriculum system that simply add or change some new courses.

Third, a basic discipline to support and faculty members are important. It's essential to have the main subject to get majors straight. Because they not only can do a favor to understand professions deeply, but also it's convenient to form primary teaching staff and support faculty development platform and it can make sure the sustainable development of the professions, or give students advices to develop. Basic teaching staff is the fundamental condition to establish professions. Teachers, especially the core teachers, such as professional leader, ought to possess accumulation of knowledge on new professions and the faculty members should be made up of more than 12 people (full-time, not with the existing professions cross-use). It must prevent 5 or 6 teachers from having a profession or more than 10 people are running 2 or 3 professions.

Of course, as undergraduate major education, it's the primary condition to have classrooms, laboratories, experiment equipments, books and so on.

\section{INFORMATION MANAGEMENT MAJOR'S REFORM UNDER THE NEW CONDITION}

Recently, there are three modes in domestic information management major to develop talents, including represented by Tsinghua university, and Tongji university of science and engineering college of industry and commerce management mode, represented by Wuhan university, Beijing university of comprehensive university information resources management mode, represented by Renmin university of China and Sun Yat-sen university information system technology oriented mode. Under new conditions, environments and demands, the rapidly development of virtual reality, Internet Plus, artificial intelligence, big data and cloud computing and so on, have exposed problems that be short of talents. There is a disconnection between engineering education and emerging economic development in China. So the information management major should be reformed in some aspects.

\section{A. Updateing Training Conception of Undergraduate}

The basic undergraduate talents training concept is updated to ensure the efficiency. First of all, it's a return to the "talent cultivation" and it can establish the foundation of the undergraduate education, define the responsibilities of teachers, and increase investment in undergraduate education of energy, strengthen foundation. The second is to promote the implement of the three advanced education concepts and it does not input the simple knowledge or basic courses requirements but rather to seek elementary abilities to deal with complex engineering problems in future for students.

\section{B. Building a continuous improvement system}

According to the "Total Quality Management Theory (PDCA)", to build a perfect continuous improvement system, the quality monitoring and the graduate tracking feedback and the social evaluation is necessary. It should ensure that it is effective and focus on growth of training targets, graduation requirements and curriculum system and continuously improve the rationality and "achievement" of the three aspects. Therefore, it needs to pay attention to some points.

Firstly, the evaluation is the foundation. Continuous enrichment requires that assessment can be a basis and it must be accurate. And the data should be reasonable and rational of analysis. It needs to clarify objects (targets) and standards (principles), executives and proper or efficient methods, appropriate cycle of valuation. It's crucial that it should be based on effective collection and in-depth analysis of that original data reflecting the objects.

Secondly, amelioration is a goal. The result of evaluation is used for improving. Insisting on improving of evaluation so as to make the reforming effective, it may emphasis on avoiding "changing" by personal feelings and experiences, opinions. It's likely to change blindly to do something that there is no depth analysis to evaluate information and cursory decision. Because of the "change" is not the "improvement".

Thirdly, the mechanism is the guarantee. It can use the mechanism to ensure continuous and valid improvement and evaluation. With the available mechanism, it can run sustainability. Setting up a series of normative process, it is fine to monitor quality, track graduates' feedback and social assessment. In addition, relevant personnel involved should shoulder their own responsibilities. 


\section{With the definite direction of resolving complex engineering problems}

It must to define the primary position of undergraduate engineering education. In order to cultivate students' ability to solve sophisticated engineering problems, it needs to design and carry out training programs for talents and evaluate the learning output according to demands. Correcting problems of some majors which have ambiguous positions and lower demands, it can reach the requirements of the ministry of education. Particularly, it's not simply to make students to participate in projects, instead it aims to apply the ability for each aspect.

\section{Strengthening and implementing the training projects of systematic design}

It must be carried out under the framework of the ministry of education. As before, it's a good idea to have a proper training target and then, realize goals to design requirements for graduating. The criteria for achieving and reaching a goal of evaluation are to be divided into a series of points. In the light of the indicators, it can accomplish the construction of curriculum system and through the practical and theoretical courses, fulfill corresponding index points. As the result of, it can reflect from graduation requirements index points. It founds places of implement that need to be improved and guided.

\section{E. Moving forward steadily to scientific teaching}

In order to get rid of the course-oriented education to reach the output-oriented education thoroughly, it's essential to use knowledge as a vehicle and give a lesson to students about how to use thoughts, methods and skills to solve complex problems of information management. Having a legible goal and it can connect to graduation indicators. And the content of course is not only the knowledge, but also it may include thoughts and methods. Therefore, the traditional outlines can't adapt to the new needs, especially, the "catalog outline" is further away from it.

\section{F. Strengthening the cooperation between production and education and enhancing the awareness and ability of innovation and entrepreneurship}

It's significant to strengthen the education awareness of cultivating talents for industries. Beyond that, "building majors according to industries' needs , constructing new structures for engineering specialty", it should actively put forward the cooperation of production and education, follow the development of technology, and train students to focus on social demands, guide them to explore and promote their awareness of innovation, entrepreneurship and ability continuously.

According to the market research report and talent demand report, universities cooperate with enterprises, and institutes to jointly develop and promote the construction of teaching resources. It pays attention to the construction of integrated train, case analysis and veritable cases of information management, and it forms a dynamic resource library that is suitable for the New Engineering talent training. It constructs a virtual simulation training base on campus and builds an internship base out of school.

\section{INFORMATION MANAGEMENT'S CONSTRUCTION BASED ON FUSION}

The key of chiastic fusion is "real fusion" instead of piecing together. Because the latter reflects the education that oriented courses, and the fusion claim that system design and implement of a professional training program for the concept of output.

1) Fusing to science and engineering, it aims to cultivate people for research and development and focus on resolving basic problems in engineering.

2) With the integration of other industries, it realizes the cross-boundary, and trains sophisticated talents, and pays attention to dealing with problems of information management in related industries. And it promotes to update and transform related industries. It's suitable for information management major which has the industry background in colleges.

3) Combining with technology development, it keeps up with it, and it's helpful to cultivate special talents and achieve the leading goals.

4) Blending into local economy, it cultivates the local construction and development talents who are more needed. Of course, as a result of information management is a common technology; there are some different and unobvious demands in different regions. At this time, It can think about special requires for local industries' development.

\section{ConClusion}

New industries, new forms, new technologies and new modes of wide application and fast development, the traditional information management professional have been unable to meet development demand in emerging economies; a new type of engineering information management personnel training is imminent.

The New Engineering construction proposed by Fudan consensus, the action of Tianjin University and Beijing guide has brought new opportunities and new reform plans to the education reform and development of higher engineering nationwide. Information management specialty in colleges and universities should take this opportunity to develop, learn and take New Engineering information management talents, having both ability and political integrity, adapted to the New Engineering information management in the development of the talent training scheme, and vigorously cultivate qualified and new technical talents, serving local industry industrial upgrading, speed up the implementation education power shift from a big engineering education project in China.

\section{ACKNOWLEDGMENT}

This work was financially supported by the National Natural Science Youth Foundation of China (71503163), and Philosophy Social Science Youth Foundation of Shanghai (2015EGL007). 


\section{REFERENCES}

[1] J.Fredericks Volkwein, Lisa R.Lattuca,Patrick T.Terenzini, Linda C.Strauss and Javzan Sukhbaatar. Engineering Change:A Study of the Impact of EC2000[J]. International Journal of Engineering Education, 2004, 20(3):318-328. $\square \square \square$

[2] Stephen T.Frezza. Creating An Accreditable Software Engineering Bachelor's Program. JEEE.Software,2006,23(6):27-35. $\square \square$

[3] Bidanda B, Arisoy O, Shuman L J. Offshoring manufacturing: Implication for engineering jobs and education : A survey and case study [J].Robotics and Computer-Integrated Manufacturing ,2006,22:576-587.
[4] Cheng Yan, etc.. SWOT Analysis on the Construction of Economic Management Courses in Local Universities under the Background of New Engineering[J]. Shandong Chemical Industry, 2017,23(46):150151.

[5] Wu Guangyuan, Lin Maohai, Li Xiaozhou. Research on the Cultivation and Construction of Printing Engineering Talents under the Background of New Engineering [J]. Journal of Higher Education, 2018,(2):164-166. 